\title{
IoT-BASED WATER QUALITY MEASUREMENT SYSTEM FOR FISH FARMING USING LoRa-WAN TECHNOLOGY
}

\author{
IVÁN D. ÁNGEL E., JULIÁN R. CAMARGO L. \& CÉSAR A. PERDOMO CH \\ Engineering Faculty, Universidad Distrital Francisco José de Caldas, Bogotá, Colombia
}

\section{ABSTRACT}

This paper presents the development of a functional prototype that allows to obtain and transmit the physicalchemical variables associated with the water quality of one or more ponds of a fish farm, implementing different electronic sensors, making use of LoRa-WAN technology; also, a stage at the software level, where a server with a relational database was developed, which allows the processing and visualization of the system information. The main function of this project is to report in real-time the variables measured by the prototype; however, it also offers the possibility of adding and managing the desired users, with different roles; this to provide a tool that allows the fish farmer to make an analysis of the behavior of their crop and encourage early decision making to reduce losses and improve the production process and quality of the final product.

KEYWORDS: Embedded System, Fish Farming, Internet of Things (IoT), LoRa-WAN, Monitoring

Received: Oct 11, 2020; Accepted: Oct 31, 2020; Published: Nov 09, 2020; Paper Id.: IJMPERDOCT202029

\section{INTRODUCTION}

Fish farming in Colombia has had a positive development both on the coast and in the interior of the country, due to the great natural wealth of this territory; however, the process of cultivating fish for human consumption requires great care and precision, since fish are animals very prone to suffer delays or alterations in their breeding, raising and fattening process, due to changes that may occur in their environment.

The main axes where the fish-raising activity is concentrated are Huila (40\%), Meta (15\%), Antioquia (7 \%), Tolima (5\%) and Cundinamarca and Boyacá (5\%); (At National level its Production reaches 84.426 Tons). Shrimp production is mainly developed in the Atlantic coast of Sucre and Bolívar (91\%); currently, a reactivation is developed on the Pacific Coast (Tumaco); with a national sector production of 3,269 tons [1].

In this type of aquaculture, it is necessary to carry out a permanent control of the quality of the water, which should not contain: residues of agricultural inputs such as insecticides, fungicides or herbicides, industrial, mining or domestic residues such as oil-based detergents. Similarly, the optimum temperature of 22 to $26^{\circ} \mathrm{C}$, minimum dissolved oxygen of $4 \mathrm{ppm}$, the acidity of 5.0 to $9.0 \mathrm{pH}$ with an ideal value of 7.5; these values may present variations depending on the species to be cultivated [2]. Frequent fertilization with animal manure or chemical fertilizers is also practiced. A concentrated feed with higher levels of protein is supplied permanently and the sowing density is programmed, which varies according to the species and the degree of exploitation. A greater technology is applied whose base is given by the continuous replenishment of water and/or aeration [3]. 
That is why it is of utmost importance to investigate the physical-chemical parameters associated with the quality of the water of the fish farms, the sensors available in the market to measure these variables, the different wireless communication technologies, the use of the internet of things and web applications, to design and implement a prototype that allows obtaining the value of the temperature, the $\mathrm{pH}$ and water level and visualize them in real-time through a web platform, since these fish farms are normally managed by the farming community for distribution and human consumption and currently have artisanal and considerably inefficient methods of measurement, which can be reflected in the quality of the food that the user will finally receive [1], [4].

The fact that this procedure is carried out manually at certain times means that there is no permanent control of the variations that occur in fish farming, which can delay the breeding, raising and fattening process, affecting the company's total production capacity and the quality of the product.

This article will emphasize the development of hardware for the implementation of the mentioned project.

\section{SYSTEM DESCRIPTION}

The development of this project has different stages, which fulfill a specific task and are integrated to ensure the proper functioning of the entire system.

This prototype offers the end-user (Figure 1), a series of functionalities that allows him to perform monitoring that integrates measurement technologies, processing and data transmission, focused on water quality in fish farms for making assertive decisions according to the status of the monitored variables.

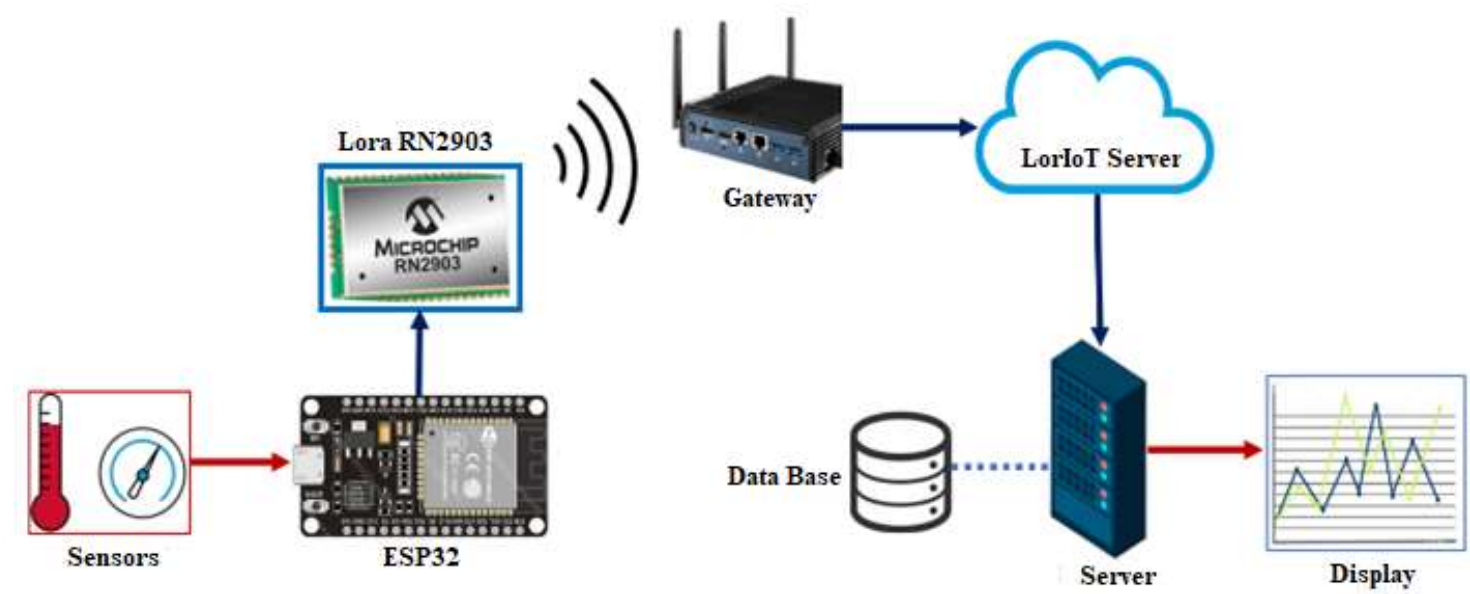

Figure 1: Diagram of the proposed system

The sensors of $\mathrm{pH}$, temperature and level are in contact with the water, these make the capture of the data and later they pass by the ESP32 so that finally the information is sent by means of technology LoRa-WAN to a server which will be in charge to visualize these data, also they will be able to be visualized by means of a LCD located in the prototype.

Subsequently, software development is proposed, which consists of a server in the backend mode, which implements a relational database and finally a server in the frontend mode, which allows the user to interact with the different functionalities and data of the system. 


\section{COMPONENTS OF THE PROTOTYPE}

Next, the different modules that make up the DataFish prototype will be explained in detail (Figure 2).

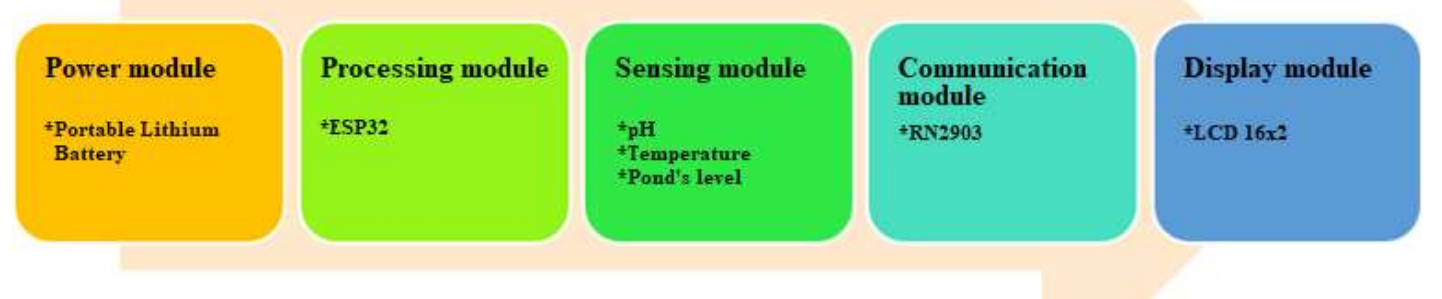

Figure 2: DataFish Prototype Modules

\subsection{Processing module}

For the choice of the embedded system, you must take into account each of the features and benefits that these would give the project to define which is the most appropriate.

According to the comparison chart shown in Table 1, it can be seen that Raspberry Pi 3 presents improvement in some features concerning the other two embedded systems, such as speed, number of pins and memory. However, the ESP32 board has a lower price than the other two boards which makes it accessible, its size is reduced to the other boards which make it easier to handle, it has an analog/digital converter already incorporated, its memory capacity and speed will allow the implementation of the whole system since it is designed to be a microcontroller for IoT. For this reason, the ESP32 is the most suitable embedded system to make the prototype for measuring the water quality in a fish farm [5].

Table 1: Comparative table between Arduino Uno, Esp32 and Raspberry pi 3

\begin{tabular}{|l|l|l|l|}
\hline Specifications & Arduino Uno & ESP32 & Raspberry pi 3 \\
\hline Price & $\$ 101.150$ & $\$ 49.980$ & $\$ 166.600$ \\
\hline Dimensions & $8 \times 5.5 \times 2.5 \mathrm{~cm}$ & $68 \times 53 \mathrm{~mm}$ & $82 \times 56 \times 19.5 \mathrm{~mm}$ \\
\hline Memory & $2 \mathrm{~KB}$ SRAM & $520 \mathrm{~KB}$ SRAM & 1 GB SDRAM \\
\hline Operating System & Doesn't have & Doesn't have & Raspbian, Windows 10 IoT Core \\
\hline IO Pins & 20 pines & 25 pines & 40 pines \\
\hline Speed & $16 \mathrm{MHz}$ & Adjustable from 80 to $240 \mathrm{MHz}$ & $1.2 \mathrm{GHz}$ \\
\hline
\end{tabular}

The ESP32 development board has a total of 30 pins connecting it to the outside world. As shown in Figure 3 [6].

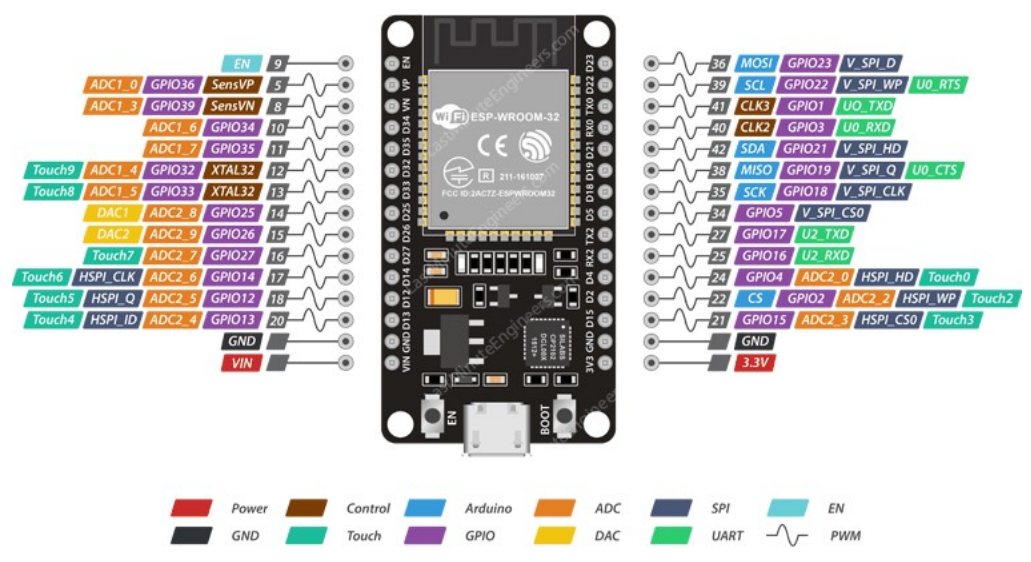

Figure 3: Esp32 Dev. Board - Pinout [5] 
Table 2 shows the technical specifications of the ESP32 module.

Table 2: Technical characteristics of the ESP32 module

\begin{tabular}{|l|l|}
\hline \multicolumn{1}{|c|}{ Specifications } & \multicolumn{1}{c|}{ ESP32 } \\
\hline Processor & $\begin{array}{l}\text { Tensilica Xtensa LX6 32 btit DualCore at } \\
160 \mathrm{MHz} \text { (up to 240 MHz) }\end{array}$ \\
\hline RAM Memory & $520 \mathrm{~KB}$ \\
\hline Flash Memory & Up to $16 \mathrm{MB}$ \\
\hline ROM & $448 \mathrm{~KB}$ \\
\hline Power & 2.2 to $3.6 \mathrm{~V}$ \\
\hline Low consumption coprocessor & Consumption less than $150 \mu \mathrm{A}$. \\
\hline WiFi & $802.11 \mathrm{~b} / \mathrm{g} / \mathrm{h}$ (up to $+20 \mathrm{dBm}) \mathrm{WEP}, \mathrm{WPA}$ \\
\hline Bluetooth & Yes \\
\hline GPIO & 11 \\
\hline PWM & 16 \\
\hline ADC & $18(12 \mathrm{bit})$ \\
\hline DAC & $2(8 \mathrm{bit})$ \\
\hline
\end{tabular}

\subsection{Sensor Module}

\subsubsection{Temperature meter DS18B20}

The DS18B20 is a digital temperature sensor that uses the 1-Wire protocol to communicate, this protocol requires only one data pin to communicate and allows you to connect more than one sensor on the same bus [7]. The DS18B20 sensor is manufactured by Maxim Integrated, the factory packaging is TO-92 type similar to that used in small transistors. The commercial presentation most used for convenience and robustness is the sensor inside a stainless steel tube water-resistant (Figure 4).

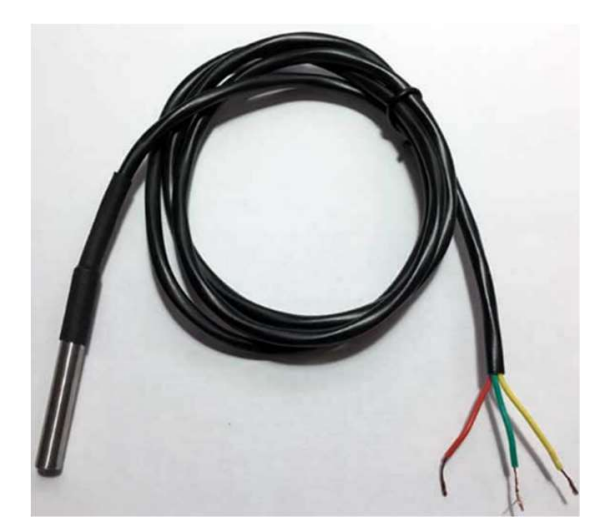

Figure 4: Temperature Sensor DS18B20

The main characteristics of the DS18B20 sensor are shown below (Table 3) [8].

Table 3: Technical characteristics of the temperature sensor DS18B20

\begin{tabular}{|l|l|}
\hline \multicolumn{1}{|c|}{ Specifications } & \multicolumn{1}{c|}{ Value } \\
\hline Supply voltage & 3v to $5 \mathrm{v}$ \\
\hline VDD & Feed pin \\
\hline GND & Ground Pin \\
\hline DQ & Data pin \\
\hline Temperature range & $-55^{\circ} \mathrm{C}$ to $125^{\circ} \mathrm{C}$ \\
\hline Accuracy & $\pm 0.5^{\circ} \mathrm{C}$ \\
\hline Programmable resolution & 9-bit, 10-bit, 11-bit or 12-bit (default) \\
\hline
\end{tabular}


Using the ESP32 board, the circuit schematic is as shown in Figure 5.

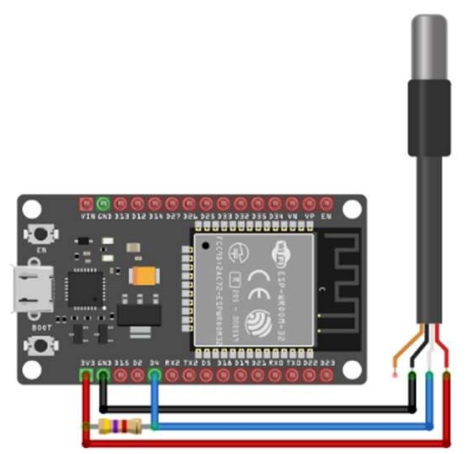

Figure 5: Schematic sensor DS18B20 (normal mode)

\subsection{2. $\mathrm{pH}$ meter}

The $\mathrm{pH}$ is a measure of acidity or alkalinity of a solution; the $\mathrm{pH}$ scale varies from 0 to 14 . The $\mathrm{pH}$ indicates the concentration of hydrogen ions $[\mathrm{H}]+$ present in certain solutions. It can be accurately quantified by a sensor that measures the potential difference between two electrodes: a reference electrode (silver/silver chloride) and a glass electrode that is sensitive to the hydrogen ion. This is what will form the probe (Figure 6).

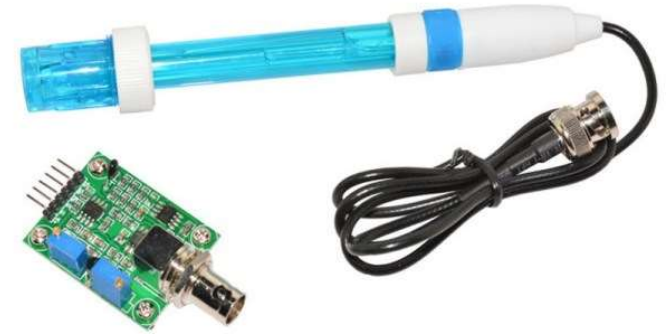

Figure 6: pH sensor

Also, an electronic circuit must be used to condition the signal properly so that we can use this sensor with a microcontroller, as with the ESP32 card as seen in Figure 7 [9].

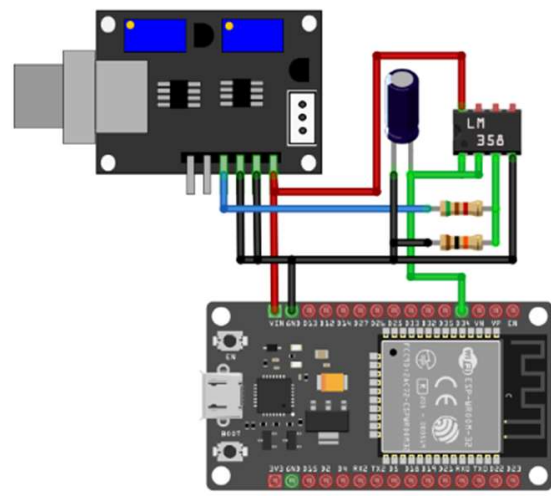

Figure 7: Schematic of a pH sensor

Calibration is important to obtain the proper $\mathrm{pH}$ value there are 2 common solutions used to measure the hydrogen potential which is $\mathrm{pH} 4.01$ and $\mathrm{pH}$ 6.86. Table 4 shows the characteristics of the $\mathrm{pH}$ sensor. 
Table 4: Technical characteristics of the $\mathrm{pH}$ sensor

\begin{tabular}{|l|l|}
\hline \multicolumn{1}{|c|}{ Specifications } & \multicolumn{1}{c|}{ Value } \\
\hline Response time & Up to 1 minute \\
\hline Accuracy & $\pm 0.01 \mathrm{pH}$ \\
\hline VCC & $5 \mathrm{~V}$ \\
\hline pH Range & $0-14$ \\
\hline Dimensions & $43 \mathrm{~mm} \times 32 \mathrm{~mm}$ \\
\hline Measuring temperature & $0-60^{\circ} \mathrm{C}$ \\
\hline
\end{tabular}

\subsubsection{Water level meter}

In this case, an ultrasound sensor is implemented, which is a device used to measure distances. Its operation is based on sending a high-frequency pulse, not audible to humans. This pulse bounces off nearby objects and is reflected in the sensor, which has a microphone suitable for that frequency [10].

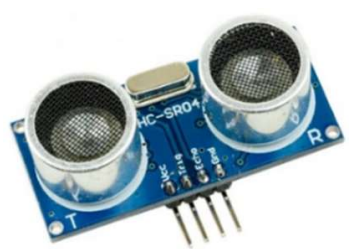

Figure 8: Ultrasound Sensor HC-SR04

The interface of the HC-SR04 sensor and the ESP32 board is achieved through 2 digital pins: the trigger and echo pins. The schematic in Figure 9 shows the sensor connection to the ESP32 board.

Table 5 shows the characteristics of the ultrasonic sensor [11].

Table 5: Technical characteristics of the ultrasound sensor

\subsubsection{Dissolved Oxygen Meter}

\begin{tabular}{|l|l|}
\hline \multicolumn{1}{|c|}{ Specifications } & \multicolumn{1}{c|}{ Value } \\
\hline Opening of the ultrasonic pulse & $15^{\circ}$ \\
\hline Accuracy & $\pm 0.3 \mathrm{~cm}$ \\
\hline VCC & $5 \mathrm{~V}$ \\
\hline Measurement range & $2 \mathrm{~cm}$ to $400 \mathrm{~cm}$ \\
\hline Pulse rate & $40 \mathrm{kHz}$ \\
\hline Measuring temperature & $0-60^{\circ} \mathrm{C}$ \\
\hline
\end{tabular}

This is a sensor that was designed to be used in the measurement of dissolved oxygen in the water and is used in applications such as environmental monitoring, aquaculture and natural sciences. The probe allows immediate data acquisition and the sensor output signal is easy to couple to control or detection systems [12]. Figure 10 shows the sensor SEN0237-A.

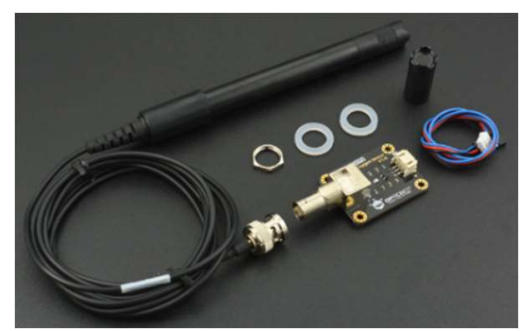

Figure 9: SEN0237-A sensor 
Some characteristics of the dissolved oxygen sensor are specified in Table 6 [13].

Table 6: Technical characteristics of the dissolved oxygen sensor

\begin{tabular}{|l|}
\hline \multicolumn{1}{|c|}{ Technical Description } \\
\hline Quality probe that does not require polarization time \\
\hline Replaceable chemical solution in the low maintenance head \\
\hline Compatible with voltages of 3.3-5V \\
\hline $0 \sim 3 \mathrm{~V}$ analog output for coupling with all types of A/D converters \\
\hline Electrode life: 1 year in normal use \\
\hline Cable length: 2 meters \\
\hline Probe connector type BNC \\
\hline
\end{tabular}

\subsubsection{Turbidity Meter}

This sensor is a compact solution in which the light source (emitting diode) and the detector (phototransistor) are mounted in the same direction. The detection of the objects is done by the reflection of the infrared beam on the surface of the objects. Its output can be analog or digital (Figure 11) [14].

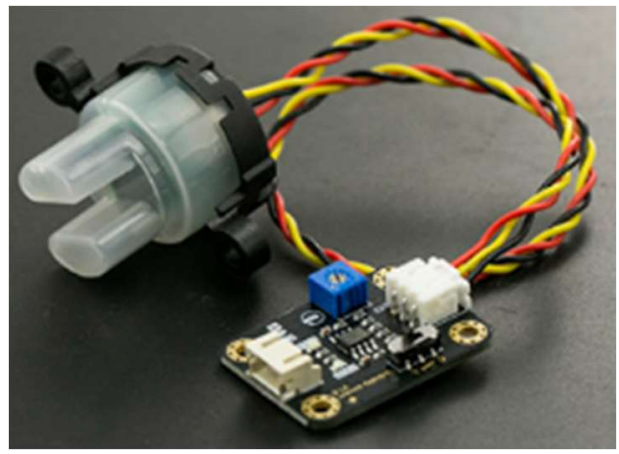

Figure 10: Turbidity Sensor SEN018

Table 7 shows the characteristics of the SEN018 Turbidity sensor.

Table 7: Technical characteristics of the turbidity sensor

\begin{tabular}{|l|l|}
\hline \multicolumn{1}{|c|}{ Specifications } & \multicolumn{1}{c|}{ Value } \\
\hline Operating current & $40 \mathrm{~mA}(\mathrm{MAX})$ \\
\hline Operating voltage & $5 \mathrm{~V}$ \\
\hline Response time & $<500 \mathrm{~ms}$ \\
\hline Analog output & $0-4.5 \mathrm{~V}$ \\
\hline Digital output & $\begin{array}{l}\text { high/low-level signal (you can adjust the } \\
\text { threshold value by adjusting the potentiometer) }\end{array}$ \\
\hline Operating Temperature & $5^{\circ} \mathrm{C}-90^{\circ} \mathrm{C}$ \\
\hline
\end{tabular}

\subsection{Data transmission module}

The RN2903 module (Figure 12) is a low power solution for long-range wireless data transmission, meets the specifications of the class A protocol of LoRa-WAN [15]. It integrates RF communication, a baseband controller and an application programming interface (API) processor, making the module a complete long-range solution. 


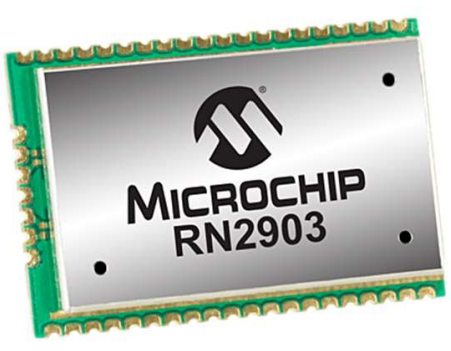

Figure 11: LoRa RN2903 module

The module is specifically designed for ease of use, which shortens development time and accelerates time to market. LoRa technology is ideal for battery operated sensors and low power applications such as IoT, M2M, Smart City, sensor networks, industrial automation and more. Table 8 shows the most relevant features of the LoRa module.

Table 8: General specifications of the RN2903 module

\begin{tabular}{|l|l|}
\hline \multicolumn{1}{|c|}{ Specifications } & \multicolumn{1}{c|}{ Description } \\
\hline Frequency band & 902.0 to $928.0 \mathrm{MHz}$ \\
\hline Modulation methods & FSK, GFSK and LoRa \\
\hline Maximum data rate & $300 \mathrm{kbps}$ in FSK, 12500 LoRa \\
\hline Interface & UART \\
\hline Range of operation & Up to $15 \mathrm{Km}$ in open area and $5 \mathrm{Km}$ in urban area \\
\hline Sensitivity to $0.1 \%$ BER & $-146 \mathrm{dBm}$ Adjustable \\
\hline Tx Power & Adjustable up to a maximum of $+18.5 \mathrm{dBm}$ \\
\hline
\end{tabular}

The LoRa RN2903 RF transceiver modules must be configured to transmit and receive point-to-point information. This type of module is designed to be used with Arduino's platform, so a study of the operation of these devices in this system is required to adapt them and use them with a microcontroller. Based on the datasheet provided by the manufacturer, some keywords are obtained followed by optional parameters to issue commands to the module (Figure 13). The commands or keywords are case sensitive, and spaces should not be used in the parameters.

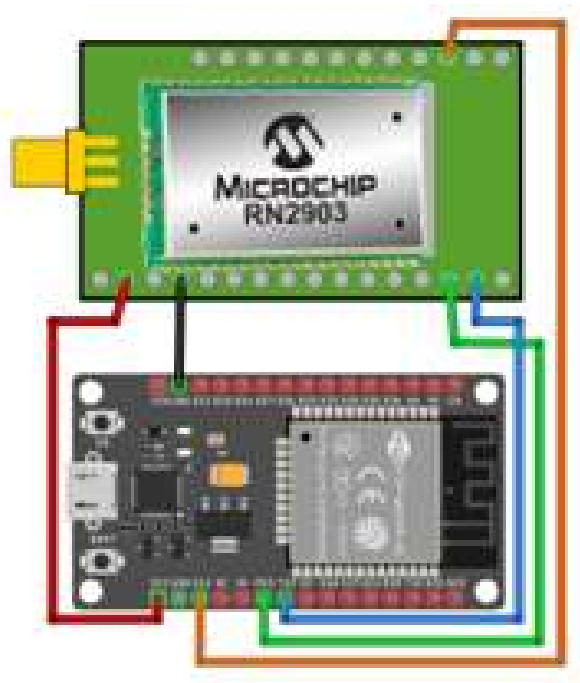

Figure 12: Schematic of data transmission (RN2903) 


\section{FINAL DESIGN}

From the data collection and data transmission section, the final design of the prototype is made using the Eagle software. A device was generated (Figure 14) that allows the connection of five (5) sensors, with visualization through a 16x2 LCD screen, with its power cable corresponding to $5 \mathrm{v}$ and direct connection to the ESP32 board.
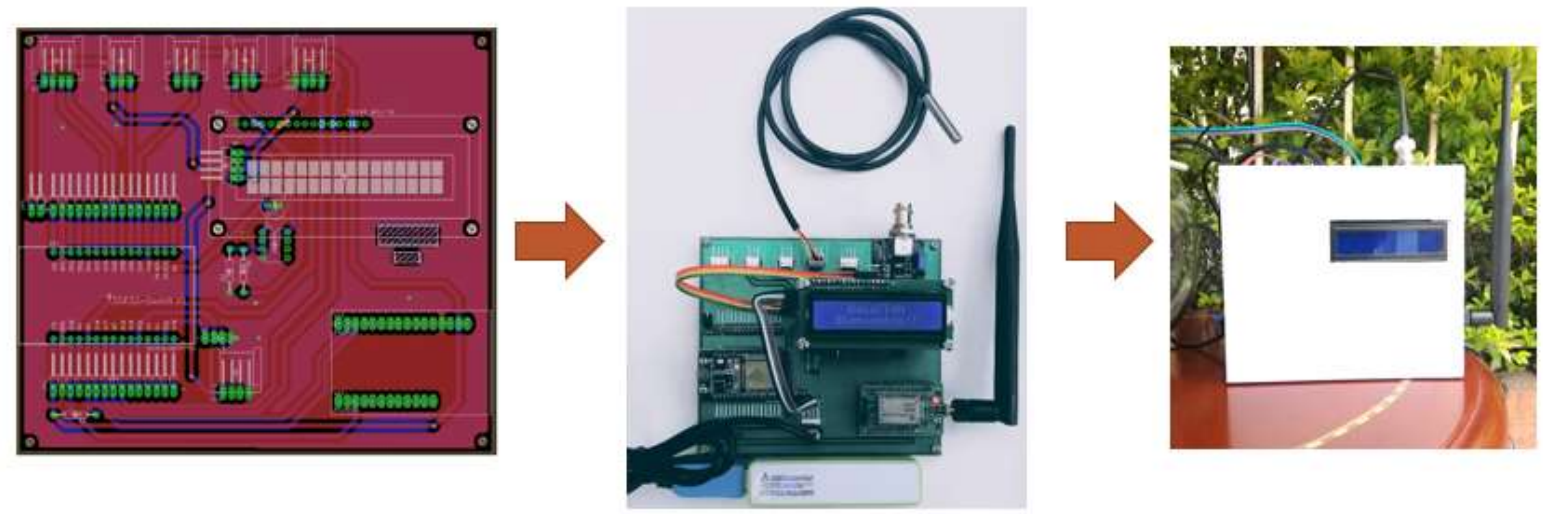

Figure 13: Final design of the DataFish prototype

\section{RESULTS}

The quality of the water in a fish farm is of utmost importance for the entire production process since variations that may occur can delay the process of breeding, raising and fattening, affecting the total production capacity of the company and the quality of the final product. For this reason, the parameters temperature, $\mathrm{pH}$, level, dissolved oxygen and turbidity were chosen to be sensed and monitored, however, these last two were emulated since they represented a very high cost for the development of the prototype.

In the measurement methods commonly used in fish farms, intermittent periods occur in the process of monitoring the water status; during these periods significant variations can occur that greatly affect the culture, which can be reflected as losses in time and raw material, which is why it is very important to implement technologies and systems such as the one developed in this project since it allows the fish farmer to perform an analysis on the status and behavior of the variables associated with water quality and considerably reduce the periods in which the status of the parameters is not known or monitored.

At the time of the proper implementation of this project, it is very important to take into account factors such as distance to the point of internet connection, existing natural and/or artificial obstacles that may affect the line of sight and alter the communication, the limitations of connection to a network point to energize the prototype, among others; that is why implementing LoRa-WAN technology is the most suitable option for this type of project, due to its network topology, energy consumption and communication scope, which allows facing and overcoming all these types of affectations.

Implementing the concept of a relational database in the system is very useful to store all the information corresponding to the users linked to the system, as well as their respective assigned crops, ponds belonging to the crops and sensors installed in each of the ponds, to maintain a constant commitment in the information obtained and store it in a totally organized and related way.

Nowadays there is great documentation on different Frameworks that facilitate the process of development as much 
at the level of backend as of frontend, of an application Web, so that to implement them is of great utility for the developer, since, due to its practicality, versatility and option of reuse, it offers multiple tools that allow him to save time and to obtain great results to interact with the information as much from the side of the servant as of the client.

\section{CONCLUSIONS}

As industrial automation accelerates, engineers are working to connect systems to the Internet of Things (IoT), which in many ways has made different industrial processes a thing of the past. However, for both new and legacy systems, wireless connectivity to IoT has become relatively simple using modules such as ESP32.

Some of the features that need to be considered when choosing a sensor are: cost, calibration, accuracy, environmental conditions and power consumption. Some of the sensors used in the project can be considered of lower performance, however, their choice was made considering the performance they offer and their price. Allowing you to meet the objective set.

The final result of this project, to graph and know the current values and the behavior that presents the sensed values, contributes enormously to the opportune decision making, which allows and is oriented, to minimize expenses and unnecessary losses, as well as to continuously improve the quality of the process and of the food that the user will receive finally.

\section{ACKNOWLEDGMENTS}

The authors would like to thank the Universidad Distrital Francisco José de Caldas and the LASER research group that supported the development and testing of the project.

\section{REFERENCES}

1. Ministerio de Agricultura y Desarrollo Rural - Sistema de Información de Gestión y Desempeño de las Organizaciones de Cadenas - SIOC. (2013). Cadena de la Acuicultura. Retrieved from: https://sioc.minagricultura.gov.co/Acuicultura/Documentos/2012-12-31\%20Cifras\%20Sectoriales.pdf\#search=baquero

2. DANE. (2014). "Insumos Factores de Producción". Retrieved from: https://www.dane.gov.co/files/investigaciones/agropecuario/sipsa/insumos_factores_de_produccion_mar_2014.pdf

3. Contraloría General de la República. (2015). "Piscicultura". Retrieved from: https://www.contraloria.gob.pa/inec/Archivos/P2051PISCICULTURA.pdf

4. Polania, N. E., Camargo, J. R. \& Perdomo, C. A. (2020). An Automation Proposal for the Fish Farming Process. International Journal of Mechanical and Production Engineering Research and Development (IJMPERD). 10(3):15825-15838.

5. Last Minute Engineers. (2020). Insight Into ESP32 Features \& Using It With Arduino IDE. Retrieved from: https://lastminuteengineers.com/esp32-arduino-ide-tutorial/

6. Sparkfun. (2016). ESP32 Datasheet. Retrieved from: https://cdn.sparkfun.com/datasheets/IoT/esp32_datasheet_en.pdf

7. Maxim Integrated. (2019). DS18B20 - Programmable Resolution1-Wire Digital Thermometer - Datasheet. Retrieved from: https://datasheets.maximintegrated.com/en/ds/DS18B20.pdf.

8. Luis del Valle Hernández. (2016). Programar fácil - DS18B20 sensor de temperatura para líquidos con Arduino. Retrieved from: https://programarfacil.com/blog/arduino-blog/ds18b20-sensor-temperatura-arduino/

9. Scidle. (2017). Cómo usar un sensor de pH. Retrieved from: https://scidle.com/es/como-usarun-sensor-de-ph-con-arduino/ 
10. Luis Llamas. (2015). Sensor de ultrasonidos HC-SR04. Retrieved from: https://www.luisllamas.es/medir-distancia-con-arduinoy-sensor-de-ultrasonidos-hc-sr04/

11. Sparkfun. (2014). Ultrasonic Ranging Module HC - SR04. Retrieved from: https://cdn.sparkfun.com/datasheets/Sensors/Proximity/HCSR04.pdf

12. Dfrobot. (2020). Sensor Oxigeno Disuelto”. Retrieved from: https://www.dfrobot.com/product-1628.html

13. State Water Resources Control Board. (2020). "Folleto Informativo - Oxígeno Disuelto (OD)". Retrieved from: https://www.waterboards.ca.gov/water_issues/programs/swamp/docs/cwt/guidance/3110sp.pdf

14. Dfrobot. (2020). Sensor Oxígeno Turbidez. Retrieved from: https://www.dfrobot.com/product-1394.html

15. Microchip. (2015). RN2903 - Low-Power Long Range LoRa® TechnologyTransceiver Module. Retrieved from: http://ww1.microchip.com/downloads/en/DeviceDoc/RN2903-Data-Sheet-DS50002390J.pdf 

